\title{
Allopurinol pretreatment improves postoperative recovery and reduces lipid peroxidation in patients undergoing coronary artery bypass grafting
}

In this prospective, randomized, double-blind, placebo-controlled study, the clinical, biochemical, and hemodynamic effects of xanthine oxidase inhibition in patients undergoing coronary artery bypass grafting were assessed. Allopurinol pretreatment significantly reduced the use of inotropic support after the operation ( 5 of 25 patients versus 13 of 25 patients, $p<0.01$ ) and increased the rate of peripheral warming $(11.4 \pm 0.85$ hours versus $14.4 \pm 1$ hours, $p<0.02)$. Twenty patients $(9$ in the allopurinol group and 11 in the placebo group) underwent invasive hemodynamic monitoring and intraoperative coronary sinus cannulation. The cardiac indexes of both groups were similar before the operation and for the first postoperative hour; thereafter, the cardiac index increased significantly in only the active treatment group $(\mathrm{F}=3.33$ and $d f=5,90, p<0.004)$. Products of lipid peroxidation (thiobarbituric acid reactive substances) increased significantly in only the placebo group, with increases being evident both in the systemic circulation $(9.5 \pm 3.2 \mathrm{nmol} / \mathrm{gm}$ albumin, $p<0.007$, and $24 \pm 5 \mathrm{nmol} / \mathrm{gm}$ albumin, $p<0.001$, at 30 seconds and 2 minutes of reperfusion, respectively) and the coronary sinus $(19.4 \pm 5.8 \mathrm{nmol} / \mathrm{gm}$ albumin, $p<0.004$, and $28 \pm 4 \mathrm{nmol} / \mathrm{gm}$ albumin, $p<0.001$, at 2 and 5 minutes of reperfusion, respectively. No significant difference was evident between the groups with respect to cardiac enzyme or vitamin $E$ release. It is proposed that xanthine oxidase inhibition exerts its beneficial effects by reducing the level of free radical activity associated with reperfusion during coronary artery bypass grafting. (J THORAC CARDIOVASC SURG 1994;107:248-56)

J. G. Coghlan, MB, MRCPI, ${ }^{a}$ W. D. Flitter, PhD, ${ }^{b}$ S. M. Clutton, BSc, ${ }^{b}$

R. Panda, MB, MS, MCh, ${ }^{a}$ R. Daly, MD, ${ }^{a}$ G. Wright, MB, LRCP, FFA, ${ }^{a}$

C. D. Ilsley, MB, MRCP, FRACP, ${ }^{\mathrm{a}}$ and T. F. Slater, PhD, FIBiol, FRCS, ${ }^{b^{\dagger}}$

Middlesex and Uxbridge, England

Is schemia/reperfusion injury during routine bypass grafting results in a measurable depression in early postoperative cardiac function (myocardial stunning) in up to $50 \%$ of patients. ${ }^{1,2}$ Myocardial stunning is widely held to

From the Department of Cardiology, Harefield Hospital, Harefield, Middlesex, ${ }^{\mathrm{a}}$ and the Department of Biology and Biochemistry, Brunal University, Kingston Lane, Uxbridge, England.

Sponsored by the British Heart Foundation.

Received for publication Dec. 2, 1992.

Accepted for publication May 4, 1993.

Address for reprints: J. G. Coghlan, MB, MRCP, Department of Cardiology, Harefield Hospital, Harefield, Middlesex UB9 6JY, England.

†Professor T. F. Slater died in April 1992.

Copyright ${ }^{\circledR} 1994$ by Mosby-Year Book, Inc.

$0022-5223 / 94 \$ 1.00+.10 \quad \mathbf{1 2} / \mathbf{1} / \mathbf{4 9 0 8 6}$ result from unchecked free radical activity ${ }^{3-7}$ and to be amenable to anti-free radical interventions. ${ }^{8-11}$ Theoretically, therefore, almost half the patients undergoing bypass operations should benefit from the administration of free radical scavengers. However, studies have failed to demonstrate evidence of myocardial free radical production in patients undergoing bypass procedures ${ }^{12,13}$ and the administration of locally active anti-free radical agents to cardioplegic solutions during bypass has yielded disappointing clinical results. ${ }^{14-16}$

Several investigators have found evidence of increased systemic free radical activity during ${ }^{12,13,17}$ and after $^{18}$ bypass operations and myocardial antioxidant defenses have been shown to be considerably impaired in this setting. ${ }^{14-16,19,20}$ It has therefore been proposed that circulating radical-generated toxins (e.g., cytotoxic aldehydes ${ }^{21}$ ) perfusing the myocardium during a period when 
Table I. Preoperative characteristics

\begin{tabular}{lccc}
\hline \multicolumn{1}{c}{ Characteristic } & $\begin{array}{c}\text { Allopurinol } \\
(\mathrm{n}=25)\end{array}$ & $\begin{array}{c}\text { Placebo } \\
(\mathrm{n}=25)\end{array}$ & $\mathrm{p}$ Value \\
\hline Angina* & & & \\
I & 1 & 1 & \\
II & 5 & 3 & \\
III & 13 & 13 & \\
IV & 6 & 8 & NS \\
Anginal mediation & & & \\
$\quad$ Nitrate & 2 & 3 & \\
$\beta$-blocker & 11 & 12 & NS \\
Calcium antagonist & 12 & 10 & \\
No. of diseased vessels & & & \\
One vessel & 0 & 3 & \\
Two vessels & 1 & 0 & \\
Three vessels & 24 & 22 & NS \\
Ejection fraction & & & \\
$\quad<40 \%$ & 2 & 0 & \\
$<50 \%$ & 2 & 5 & \\
$\quad+50 \%$ & 21 & 20 & \\
Average\% \pm SEM & $62 \pm 2.5$ & $63 \pm 2.4$ & NS \\
Age (yr) & & & \\
34-49 & 4 & 5 & NS \\
50-65 & 15 & 14 & \\
$\quad$ +65 & 6 & 6 & \\
Average \pm SEM & $57 \pm 1.8$ & $59 \pm 1.9$ & NS \\
Female & 3 & 5 & NS \\
Diabetes & 4 & 3 & NS \\
Previous MI & 9 & 8 & NS \\
\hline Con & & & \\
\hline
\end{tabular}

Continuous data are expressed as mean \pm standard error of the mean. Categorical data are presented in toto. Previous MI, Myocardial infarction more than 6 months before operation; $S E M$, standard error of the mean.

*New York Heart Association classification.

antioxidant defenses are low produces myocardial oxidative stress and stunning. ${ }^{12,17,18}$ Although unproved, this theory provides a logical explanation for the limited clinical benefits associated with the use of direct free radical scavenging agents administered only during myocardial ischemia.

Allopurinol prophylaxis in patients undergoing coronary artery bypass graft (CABG) operation has, by contrast, yielded clinical ${ }^{22,23}$ and biochemical benefits. ${ }^{24}$ Inhibition of free radical activity has been proposed as the mechanism of action. Allopurinol is a poor direct scavenger of radical species ${ }^{25}$ but produces almost complete inhibition of the superoxide-generating enzyme xanthine oxidase. Xanthine oxidase is virtually absent from the heart ${ }^{26-28}$; thus suppression of systemic production of radical species must be invoked. If, therefore, allopurinol prophylaxis acts through inhibition of radical activity, it should be possible to demonstrate a reduction in indexes of radical activity in the systemic or coronary circulations, or both, in patients undergoing bypass procedures.

In this study we assess the impact of allopurinol therapy on the clinical and hemodynamic recovery during the
Table II. Surgical details

\begin{tabular}{|c|c|c|c|}
\hline Procedures & $\begin{array}{c}\text { Allopurinol } \\
(\mathrm{n}=25)\end{array}$ & $\begin{array}{l}\text { Placebo } \\
(\mathrm{n}=25)\end{array}$ & p Value \\
\hline \multicolumn{4}{|l|}{ Total grafts } \\
\hline 1 & 0 & 3 & \\
\hline 2 & 1 & 0 & \\
\hline 3 & 9 & 5 & \\
\hline 4 & 11 & 13 & \\
\hline 5 & 3 & 4 & \\
\hline 6 & 1 & 0 & \\
\hline Average & 3.8 & 3.6 & NS \\
\hline \multicolumn{4}{|l|}{ Mammary grafts } \\
\hline 0 & 1 & 3 & \\
\hline 1 & 23 & 21 & \\
\hline 2 & 1 & 1 & NS \\
\hline Endarterectomy & 1 & 1 & \\
\hline Aneurysectomy & 1 & 0 & \\
\hline \multicolumn{4}{|l|}{ Surgeon } \\
\hline No. 1 & 7 & 7 & \\
\hline No. 2 & 7 & 6 & \\
\hline No. 3 & 9 & 8 & \\
\hline No. 4 & 2 & 4 & NS \\
\hline $\begin{array}{l}\text { Total ischemic time } \\
(\min \pm \text { SEM })\end{array}$ & $48 \pm 3.4$ & $41 \pm 4.4$ & NS \\
\hline $\begin{array}{l}\text { Total pump time } \\
(\min \pm \text { SEM })\end{array}$ & $113 \pm 5.2$ & $120 \pm 7.7$ & NS \\
\hline
\end{tabular}

Continuous data are presented as mean \pm standard error of the mean, and categorical da ta are presented in toto. Left internal mammary arteries were routinely used. Free right mammary grafts were used in two patients. SEM, Standard error of the mean.

first postoperative day. In addition, we examine the effect on an index of free radical activity (lipid peroxidation) in both the systemic and coronary sinus blood during the first minutes of myocardial reperfusion in patients undergoing $\mathrm{CABG}$ operation.

\section{Patients and methods}

Patient population. We studied patients with stable or unstable angina undergoing their first CABG operation in whom full revascularization was expected and who had not previously experienced an episode of clinical cardiac failure. Ethical approval was provided by the Hillingdon Health Authority ethical committee, with the provision that invasive studies were performed only in patients with low risk operated on by consultant staff. Informed consent was obtained in each case, and invasive monitoring and coronary sinus cannulation were performed when written consent was obtained. Details of the patient population according to their randomization are given in Table I.

Randomization and blinding. Two tablets of allopurinol $(300 \mathrm{mg}$ ) or an identical placebo were placed in identical containers and assigned numbers 1 through 50 according to a table of random numbers. Each consecutive patient was assigned the next available numbered container and identified thereafter by their hospital and study numbers. The code remained unbroken throughout the study and was broken only after all clinical and hemodynamic data had been collected and all biochemical analyses had been performed. 
Table III. Clinical outcome

\begin{tabular}{|c|c|c|c|}
\hline Parameter & $\begin{array}{c}\text { Allopurinol } \\
(\mathrm{n}=25)\end{array}$ & $\begin{array}{l}\text { Placebo } \\
(\mathrm{n}=25)\end{array}$ & $\mathrm{p}$ Value \\
\hline Inotrope Rqd & 5 & 13 & $<0.01$ \\
\hline Ep/NEp & 2 & 8 & NA \\
\hline Duration of support $>24 \mathrm{hr}$ & 1 & 6 & NA \\
\hline \multicolumn{4}{|c|}{ Mean dopamine dose \pm SEM $(\mu \mathrm{g} / \mathrm{kg}$ per minute $)$} \\
\hline $0-12 \mathrm{hr}$ postoperative & $2.1 \pm 0.3$ & $3.1 \pm 0.6$ & $<0.08$ \\
\hline 12-24 hr postoperative & $2.0 \pm 0.4$ & $3.2 \pm 0.7$ & $<0.08$ \\
\hline \multicolumn{4}{|c|}{ Mean nitrate dose \pm SEM $(\mathrm{mg} / \mathrm{hr})$} \\
\hline $0-12 \mathrm{hr}$ postoperative & $5.2 \pm 0.8$ & $5.2 \pm 0.9$ & NS \\
\hline 12-24 hr postoperative & $2.1 \pm 0.7$ & $2.8 \pm 0.7$ & NS \\
\hline Warming time $(\mathrm{hr})^{*}$ & $11.4 \pm 0.9$ & $14.4 \pm 1$ & $<0.015$ \\
\hline Arrhythmia & 4 & 6 & NA \\
\hline Acidemia $\dagger^{-}$ & 6 & 6 & NS \\
\hline Oliguria $\ddagger$ & 8 & 7 & NS \\
\hline Ventilation (hr) & $11.5(9.5-15.5)$ & $14(11-20)$ & NS \\
\hline ITU stay (hr) & $21(18.5-41)$ & $25(20.5-54.5)$ & NS \\
\hline CNS & 1 & 3 & NA \\
\hline MI & 1 & 2 & NA \\
\hline Death & 1 & 1 & NA \\
\hline
\end{tabular}

Inotrope Rqd, Administration of inotropic agent for hypotension (see Patients and Methods section ); $E p / N E p$, epinephrine or norepinephrine support required; $N A$, not assessed because of insufficent data points; $S E M$, standard error of the mean; $I T U$, intensive therapy unit; $C N S$, postoperative confusional state; $M I$, intraoperative $Q$ wave infarct.

${ }^{*}$ Hours after the operation for the peripheral temperature to reach $35^{\circ} \mathrm{C}$.

$\dagger$ Base excess greater than $5 \mathrm{mmol}$.

†Urine output averaging less than $160 \mathrm{ml}$ in any 4-hour period or diuretic given.

Administration of study drug. Each patient received one tablet at $8 \mathrm{PM}$ on the evening before the operation and one tablet with their premedication (1 hour before the operation).

Surgical technique. A standard cardiopulmonary bypass technique was used throughout the study. The same roller pump (Cobe Laboratories, Lakewood, Colo.) and membrane oxygenator (Maxima; Medronic, Inc., Cardiopulmonary Division, Anaheim, Calif.) were used for all patients. The extracorporeal circuit was primed with Ringer's lactate solution $1.5 \mathrm{~L}$ and mannitol $100 \mathrm{ml}$. In 37 patients, myocardial preservation was effected with moderate hypothermia $\left(30^{\circ}\right.$ to $32^{\circ} \mathrm{C}$ ) and intermittent ischemic arrest (including all patients in whom invasive monitoring was performed); in 13 patients, cardioplegic arrest $\left(28^{\circ} \mathrm{C}\right.$; $1 \mathrm{~L}$ of St. Thomas' Hospital solution II in Ringer's lactate solution), repeated every half hour. The perfusion pressure was maintained between 50 and $70 \mathrm{~mm} \mathrm{Hg}$ during bypass by varying pump speed ( 2.2 to 2.4 cardiac index) and, where necessary, by the use of methoxamine (bolus 1 to $5 \mathrm{mg}$ ) or nitrate infusion. With intermittent arrest, the heart was defibrillated within 2 minutes of reperfusion in each case. In those patients who underwent cardioplegia, the heart was restarted electrically or spontaneously when core temperature exceeded $33^{\circ} \mathrm{C}$. For each patient, the number of grafts placed, the duration of bypass, and the duration of crossclamping was noted.

Patient cannulation. For routine procedures each patient had a 20-gauge radial arterial line, and a 14-gauge venous line placed immediately before anesthesia was induced. Intubation and placement on an internal jugular line was performed after anesthesia. In addition, 20 patients had thermodilution Swan-
Table IV. Influence of cardioplegia on outcome

\begin{tabular}{|c|c|c|c|}
\hline Parameter & $\begin{array}{c}\text { Intermittent } \\
\text { crossclamp } \\
(\mathrm{n}=37)\end{array}$ & $\begin{array}{l}\text { Cardioplegia } \\
\quad(\mathrm{n}=13)\end{array}$ & p Value \\
\hline Total ischemic time ( $\mathrm{min})$ & $7.6 \pm 2.47$ & $65.2 \pm 4.9$ & $<0.001$ \\
\hline Initial postop temp $\left({ }^{\circ} \mathrm{C}\right)$ & 0.32 & $29.1 \pm 0.39$ & NS \\
\hline Rewarming time $(\mathrm{hr})$ & $13.4 \pm 0.9$ & $11.4 \pm 0.76$ & NS \\
\hline Inotrope use & $14 / 37$ & $4 / 13$ & NS \\
\hline $\begin{array}{l}\text { Mean dopamine }(\mu \mathrm{g} / \mathrm{kg} \text { per } \\
\text { minute)* }\end{array}$ & $2.7 \pm 0.4$ & $2.2 \pm 0.6$ & NS \\
\hline Mean GTN $(\mathrm{mg} / \mathrm{hr})^{*}$ & $5.0 \pm 0.6$ & $5.7 \pm 1.5$ & NS \\
\hline
\end{tabular}

Continuous data are presented as mean \pm standard error of the mean. Initial postop temp, Peripheral temperature on return to intensive care unit; $G T N$, glyceryl trinitrate.

*Dose administered over the first 12 postoperative hours.

Ganz catheters (Baxter Healthcare Corp., Edwards Division, Irvine, Calif.) placed through an $8.5 \mathrm{~F}$ jugular sheath at this time. After routine aortic and right atrial cannulation but immediately before bypass, a $14 \mathrm{~F}$ retrograde coronary sinus cannula (RC-014-MIBB; Research Medical Inc., Midvale, Utah) was inserted via the lower right atrium.

Sampling and analysis. Paired coronary sinus and arterial blood samples were taken after 5 to 10 minutes of bypass, and 30 seconds, 2,5 , and 10 minutes after the final period of reperfusion (when core temperature had been restored to $37^{\circ} \mathrm{C}$ ). Thiobarbituric acid reactive substances (TBArs) were measured on plasma samples anticoagulated with potassium ethylenediaminetetraacetic acid with the technique described by Yagi. ${ }^{29}$ Vitamin E was also measured on potassium ethylenediaminetetraacetic acid-anticoagulated plasma with the technique described by Burton, Webb, and Ingold. ${ }^{30}$ Routine spectrophotometric analysis of serum by Sigma diagnostic kits (Sigma Chemical Co., St. Louis, Mo.) was performed to assess hydroxybutyrate dehydrogenase aspartate transaminase, albumin, and cholesterol.

Perioperative management. Glyceryl trinitrate was administered to all patients after the operation: a dose of 2 to $5 \mathrm{mg} / \mathrm{hr}$ was routine; higher doses of glyceryl trinitrate and, where necessary, sodium nitroprusside were given if the systolic blood pressure exceeded $120 \mathrm{~mm} \mathrm{Hg}$. Dopamine was administered routinely in a "renal" dose ( 2 to $5 \mu \mathrm{g} / \mathrm{kg}$ per minute). Inotropic support was instituted if the systolic blood pressure remained less than $95 \mathrm{~mm} \mathrm{Hg}$ despite adequate filling (central venous pressure 10 to $12 \mathrm{~mm} \mathrm{Hg}$ ). The inotrope of choice was dopamine, in doses between 5 and $15 \mu \mathrm{g} / \mathrm{kg}$ per minute; adrenaline or, more rarely, noradrenaline was added if the response was inadequate.

Hemodynamic data. Central venous, mean pulmonary artery, pulmonary artery wedge, and mean arterial pressures, heart rate, and cardiac output (thermodilution) were determined before bypass and 30 minutes, 1, 4, 8, and 24 hours after the end of bypass. Pulmonary artery wedge pressure was kept between 8 and $17 \mathrm{~mm} \mathrm{Hg}$, and higher levels were attained by colloid administration where the cardiac index was less than 2.5 or the systolic blood pressure was below $95 \mathrm{~mm} \mathrm{Hg}$.

Clinical data. The performance of patients was assessed at intervals of 4 hours from the end of bypass for 24 hours. Further adverse events occurring during their hospitalization were 


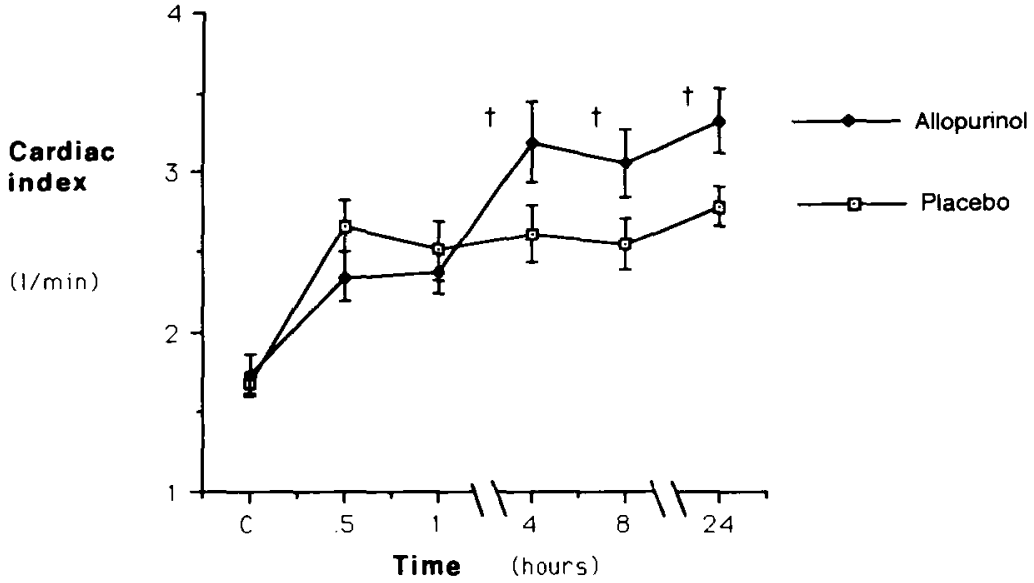

Fig. 1. Graph of cardiac index against time during the first postoperative day. Values on $x$ axis are hours after bypass. $C$, Control recordings taken immediately before cannulation for bypass; $f$, at 4,8 , and 24 hours after bypass, the cardiac index in those patients who received allopurinol exceeded the prebypass cardiac index $(p<0.001)$ and the initial postbypass cardiac index after bypass $(p<0.02)$.

Table V. Early postoperative hemodynamic variables $(\mathrm{n}=20$, invasive monitoring)

\begin{tabular}{|c|c|c|c|c|c|c|c|}
\hline \multirow[b]{2}{*}{ Parameter } & \multirow[b]{2}{*}{$R x$} & \multirow[b]{2}{*}{ Pre } & \multicolumn{5}{|c|}{ Hours after bypass } \\
\hline & & & 0.5 & 1 & 4 & 8 & 24 \\
\hline \multirow[t]{2}{*}{$\mathrm{Q} / \mathrm{m}^{2}(\mathrm{~L} / \mathrm{min}$ per square meter $)$} & $P$ & $1.7 \pm 0.07$ & $2.7 \pm 0.16^{*}$ & $2.5 \pm 0.19$ & $2.6 \pm 0.18$ & $2.6 \pm 0.16$ & $2.8 \pm 0.12^{*}$ \\
\hline & A & $1.7 \pm 0.12$ & $2.3 \pm 0.15$ & $2.4 \pm 0.12^{*}$ & $3.2 \pm 0.25 t$ & $3.1 \pm 0.21 \dagger$ & $3.3 \pm 0.20 \dagger$ \\
\hline \multirow[t]{2}{*}{ LVSWI $\left(\mathrm{gm} / \mathrm{m}^{2}\right)$} & $\mathbf{P}$ & $20.8 \pm 2.2$ & $22.9 \pm 1.5$ & $23.5 \pm 2.1$ & $21.9 \pm 2.2$ & $20.7 \pm 1.8$ & $23.9 \pm 1.7$ \\
\hline & A & $24.6 \pm 1.9$ & $21.8 \pm 1.7$ & $24.3 \pm 2.1$ & $26.4 \pm 1.8$ & $25.0 \pm 1.7$ & $31.3 \pm 3.5$ \\
\hline \multirow[t]{2}{*}{ PCWP (mm Hg) } & $\mathbf{P}$ & $7.6 \pm .92$ & $10.7 \pm 1.3^{*}$ & $10.9 \pm 0.91 *$ & $10.5 \pm 0.77$ & $12.2 \pm 0.66^{*}$ & $11.4 \pm 0.85^{*}$ \\
\hline & A & $7.6 \pm 0.58$ & $9.7 \pm 0.77$ & $11.1 \pm 1.1^{*}$ & $10.6 \pm 0.99$ & $10.6 \pm 0.48^{*}$ & $11.2 \pm 1.2$ \\
\hline \multirow[t]{2}{*}{ Mean AP (mm Hg) } & $\mathbf{P}$ & $72.4 \pm 3.2$ & $72.4 \pm 3.9$ & $73.5 \pm 4.0$ & $70.4 \pm 2.5$ & $68.4 \pm 2.3$ & $72.8 \pm 1.9$ \\
\hline & A & $82.7 \pm 4.0$ & $76.8 \pm 3.5$ & $79.0 \pm 2.8$ & $73.0 \pm 2.8$ & $70.6 \pm 3.4$ & $79.4 \pm 5.1$ \\
\hline \multirow[t]{2}{*}{ Heart rate (beats/min) } & $\mathbf{P}$ & $72.2 \pm 4.4$ & $96.4 \pm 7.4^{*}$ & $93.6 \pm 8.3^{*}$ & $98.2 \pm 5.3^{*}$ & $96.5 \pm 5.4^{*}$ & $97.3 \pm 4.4 \dagger$ \\
\hline & A & $71.2 \pm 3.8$ & $93.6 \pm 8.0^{*}$ & $92.4 \pm 6.7^{*}$ & $102 \pm 5.2 \dagger$ & $98.1 \pm 4.2 \dagger$ & $95.9 \pm 5.4 \dagger$ \\
\hline
\end{tabular}

Data are mean \pm standard error of the mean. $R x$. Treatment group; Pre, prebypass (control) value; $Q / m^{2}$, cardiac index; $P$, placebo group; $A$, allopurinol group; $L V S W I$, left ventricular stroke work index; $P C W P$, pulmonary capillary wedge pressure; Mean $A P$, mean arterial pressure.

*Significantly change from control value $(p<0.01)$.

tSignificantly change from control value $(p<0.001)$.

documented from the case notes. Data obtained during the first 24 hours included the following: blood pressure, urine output, peripheral temperature, inotropic support, vasodilator administration, and acid base balance averaged for each 4-hour period. Adverse events included the following: arrhythmias, hemorrhage, reoperation, neurologic events, and myocardial infarction (evidenced by new $Q$ waves). The duration of ventilation and stay in the intensive therapy unit was also noted.

Statistics. Data are presented as mean \pm standard error of the mean (normal data) or median \pm interquartile range (nonparametric data). Continuous, normally distributed data were analyzed by $t$ testing (for single comparisons) or repeated measures analysis of variance (multiple comparisons) with a grouping factor where appropriate and standard tests for correlation. Continuous nonnormal data were analyzed with the MannWhitney $U$ test, and categorical data were analyzed with a $\chi^{2}$ test. Results were regarded as significant where $p<0.05$ (sin- gle-tailed analysis), and the Bonferonni correction was used where three or more data points were tested.

\section{Results}

The two patient groups did not differ significantly with respect to preoperative risk status (Table I) or operative conduct (Table II).

Clinical outcome. Two patients died during the study (one from each group): both had a low-output state that developed within hours of the operation for which no cause could be determined on reopening of the chest. Despite inotropic support and intraaortic balloon pumping, their low-output state continued and renal and subsequent hepatic failure developed. The patients 


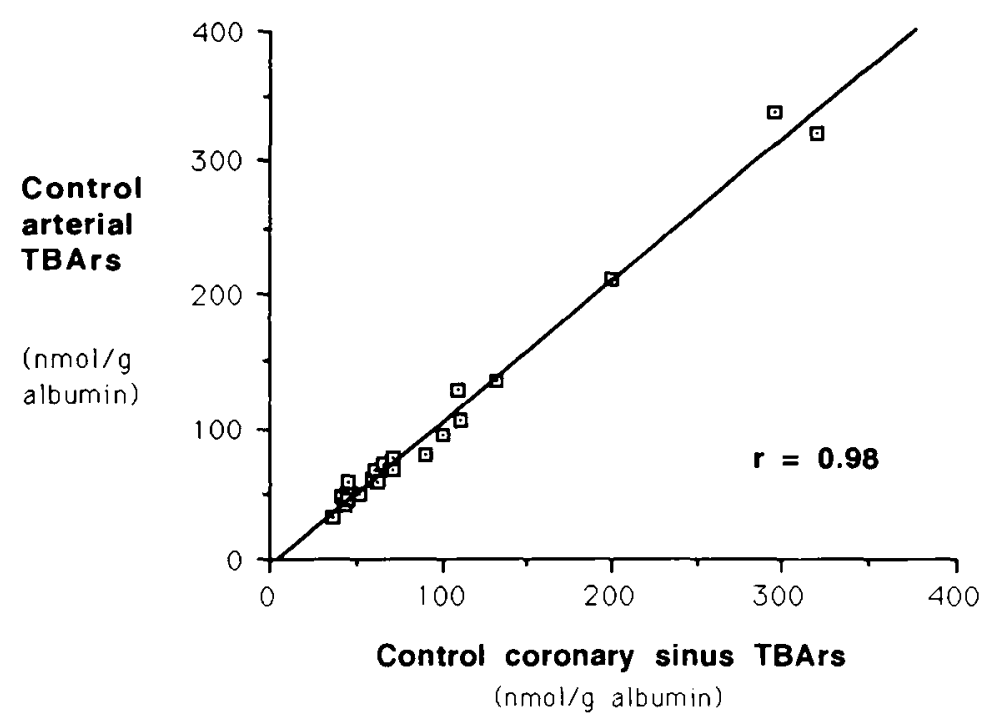

Fig. 2. Scatter graph illustrating the high degree of reproducibility of the TBArs assay. Note the considerable variation in control TBArs levels recorded during this study ( 44 to $320 \mathrm{nmol} / \mathrm{gm}$ albumin). Because two control levels were obtained from each patient (one arterial and one coronary sinus), the degree of intraindividual reproducibility was examined.

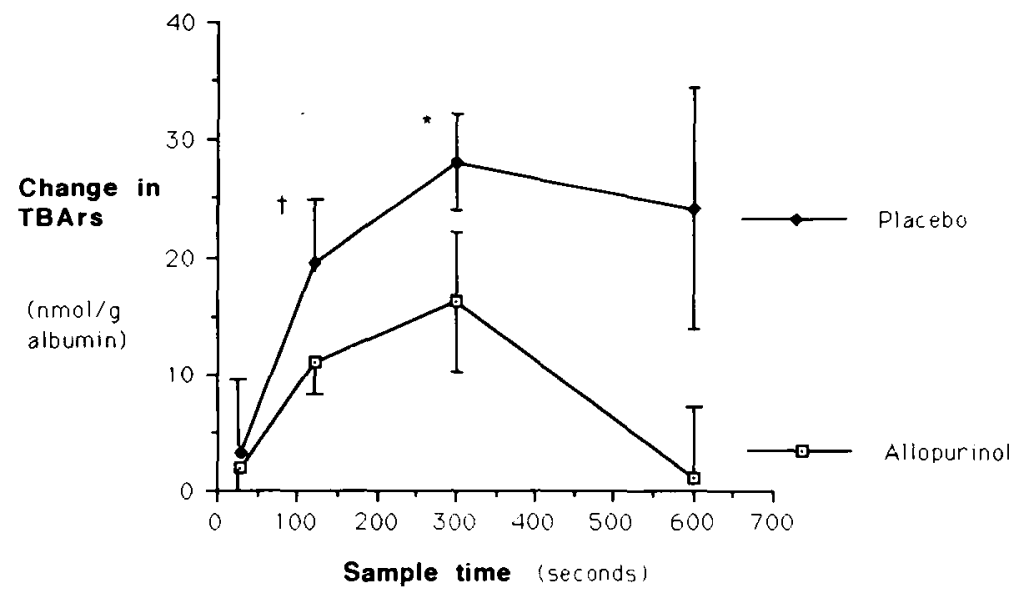

Fig. 3. Increase over control TBArs levels recorded in the coronary sinus according to treatment group (allopurinol or placebo) at each sampling time after crossclamp removal (mean \pm standard error of the mean). Significant increases over baseline were recorded only in the placebo group. $f, p<0.004 ; *, p<0.001$.

died at 17 and 21 days after the operation. Table III details the clinical outcome after operation for both groups.

All patients received nitrates after the operation. The mean dosage over the first 12 hours (during rewarming) was almost identical: $5.17 \pm 0.9 \mathrm{mg} / \mathrm{hr}$ in the placebo group and $5.24 \pm 0.8 \mathrm{mg} / \mathrm{hr}$ in the allopurinol group. Only three patients (two in the allopurinol group) required sodium nitroprusside infusion to maintain systolic blood pressure below $120 \mathrm{~mm} \mathrm{Hg}$. The peripheral temperature on return to the intensive care unit was similar in both groups $28.4 \pm 0.5^{\circ} \mathrm{C}$ for the placebo group and $28.7 \pm 0.6^{\circ} \mathrm{C}$ for the allopurinol group; $p=$ [NS]). However, the mean rewarming time for the allopurinol group group was less than that of the placebo group (Table III).

Table III shows that the mean dose of dopamine was marginally but not significantly higher in the placebo group. However, fewer patients who received allopurinol required inotropes (Pearson $\chi^{2}$ test $5.6 ; p<0.01$, Table 
III). Although more patients in the placebo group received adrenaline or noradrenaline infusions and required inotropic support for more than 24 hours after the operation, the small number of patients involved render statistical analysis unreliable. Although not significant, fewer patients with active treatment required pacing, had postoperative confusion, and spent less time in the intensive therapy unit.

Influence of cardioplegia. Table IV shows that the patients who underwent cardioplegia had significantly longer total ischemic times but were otherwise similar to the remainder of the group. Eight of the patients who underwent cardioplegia were randomized to the active treatment group versus five to the placebo group $(p=\mathrm{NS})$. Excluding the patients protected with cardioplegia, the cumulative duration of crossclamping was slightly longer in the those patients who received allopurinol $(40.7 \pm 3.2$ minutes versus $33.5 \pm 3.5$ minutes; $p=\mathrm{NS})$. In the 37 patients protected with intermittent crossclamping, the mean time to rewarm was less in the allopurinol group $(11.53 \pm 1.2$ hours versus $15 \pm 1.3$ hours; $t=2.01, p<0.03$ ) and inotrope usage was less frequent ( 4 of 17 patients versus 10 of 20 patients; Pearson $\chi^{2}$ test $\left.2.74, p<0.05\right)$. None of the patients undergoing invasive hemodynamic assessment underwent cardioplegia.

Hemodynamic outcome. Indexes of cardiac function recorded after induction of anesthesia depended largely on the adequacy of anesthesia. Thus, low cardiac indexes before the operation were found in all patients, and no significant differences were found between the treatment groups. After the operation, the cardiac index was initially slightly higher in the placebo group but failed to increase significantly over the next 24 hours. By contrast, the cardiac index rose sharply between 30 minutes and 4 hours after the operation in the active treatment group $(\mathrm{F}=6.35, d f=8 ; p<0.02)$ and remained greater than $3 \mathrm{~L} / \mathrm{m}^{3}$ thereafter. Repeated measures analysis of variance confirmed that the increase in cardiac output in the active treatment group significantly exceeded that recorded in the placebo group ( $\mathrm{F}=3.3, d f=5,90 ; p<0.004)$. The difference between the absolute cardiac indexes for the two groups approached significance at three individual time points: 4 hours $(p<0.04), 8$ hours $(p<0.04)$, and 24 hours after bypass ( $p=0.015$, Fig. 1). The cardiac indexes of the treatment group significantly exceeded those of the placebo group from 4 hours after bypass $(\mathrm{F}=8.07, d f=1,18 ; p<0.006)$. No significant differences in preload, afterload, or heart rate between the groups was found at any time before or after the operation (Table V). Left ventricular stroke work index in the active treatment group significantly exceeded that of the placebo group from 4 hours after the operation $(\mathrm{F}=5.48$, $d f=1,18 ; p<0.016)$.

Lipid peroxidation. The circulating levels of TBArs at baseline varied considerably among patients, ranging from $44 \mathrm{nmol} / \mathrm{gm}$ albumin to $320 \mathrm{nmol} / \mathrm{gm}$ albumin. The reproducibility of the test was excellent, and the comparison of the two baseline samples obtained from each patient (one arterial, one coronary sinus) gives an $r$ value of 0.98 (Fig. 2).

Fig. 3 shows the change with time for TBArs in the coronary sinus for each group. In the placebo group, the coronary sinus TBArs concentration increased from a control value of $95 \pm 24 \mathrm{nmol} / \mathrm{gm}$ albumin to $114 \pm 26$ $\mathrm{nmol} / \mathrm{gm}$ albumin at 2 minutes $(+19 \pm 5.8 \mathrm{nmol} / \mathrm{gm}$ albumin; $\mathrm{F}=11, p<0.004)$ and to $122 \pm 26 \mathrm{nmol} / \mathrm{gm}$ albumin at 5 minutes reperfusion $(+28 \pm 4 \mathrm{nmol} / \mathrm{gm}$ albumin; $\mathrm{F}=48$; $p<0.001$ ). An increase over the control level of $98 \pm 24 \mathrm{nmol} / \mathrm{gm}$ albumin in circulating TBArs was also found in the arterial circulation both at 30 seconds (108 $\pm 25 \mathrm{nmol} / \mathrm{gm}$ albumin representing a change of $+9.5 \pm 3.2 \mathrm{nmol} / \mathrm{gm}$ albumin; $\mathrm{F}=8.73$; $p<0.007)$ and 2 minutes $(122 \pm 28 \mathrm{nmol} / \mathrm{gm}$ albumin, an increase of $24 \pm 5 \mathrm{nmol} / \mathrm{gm}$ albumin; $\mathrm{F}=23.5$; $p<0.001$ ) after crossclamp removal (Table VI). For the active treatment group, a much smaller (nonsignificant) increase in TBArs was observed again in both the coronary sinus and arterial blood. No significant arteriocoronary sinus difference was observed at any time in either group.

The net increase in products of peroxidation in the coronary sinus blood (expressed as area under the curve increase in TBArs concentration) was significantly less in those patients who received allopurinol $(93.5 \pm 40.2$ $\mathrm{nmol} \mathrm{min} / \mathrm{gm}$ albumin) than in the placebo group $(219.4 \pm 40.2 \mathrm{nmol} \mathrm{min} / \mathrm{gm}$ albumin, $t=-2.2, d f=18$; $p<0.02)$. A trend toward a greater net increase in circulating (arterial) products of peroxidation was also evident in the placebo group $(179.5 \pm 67.6 \mathrm{nmol} \mathrm{min} / \mathrm{gm}$ albumin versus $83 \pm 59 \mathrm{nmol} \mathrm{min} / \mathrm{gm}$ albumin in the active group; $t=-1.1, d f=18 ; p<0.15)$.

Net TBArs release (area under the curve) was independent of control vitamin $\mathrm{E}$ levels, cardiac enzyme release (multivariate regression analysis), and duration of aortic crossclamping (Spearman's test) in both the placebo group alone and the whole group combined.

Vitamin E. A net myocardial loss of vitamin E was found 30 seconds after reperfusion in the placebo group $(-0.96 \pm 0.3 \mu \mathrm{mol} / \mathrm{mmol}$ cholesterol; $\mathrm{F}=9.9, d f=10$; $p<0.01$ ). Table VI shows this net loss of vitamin $\mathrm{E}$ to come partly from a slight reduction of arterial vitamin $E$ levels and partly from a slight increase in coronary sinus vitamin $E$ levels. No significant differences were present 
Table VI. Biochemical parameters $(\mathrm{n}=20$, invasive monitoring)

\begin{tabular}{|c|c|c|c|c|c|c|c|c|c|c|}
\hline \multirow[b]{2}{*}{ Parameter } & \multicolumn{5}{|c|}{ Coronary sinus } & \multicolumn{5}{|c|}{ Arterial } \\
\hline & $C$ & 30 & 120 & 300 & 600 & $C$ & 30 & 120 & 800 & 600 \\
\hline \multicolumn{11}{|c|}{ TBArs (nmol/gm albumin) } \\
\hline Allopurinol & 110 & 112 & 121 & 126 & 111 & 112 & 120 & 125 & 120 & 118 \\
\hline SEM & 28 & 27 & 27 & 27 & 26 & 32 & 30 & 31 & 27 & 32 \\
\hline Placebo & 95 & 98 & 114 & 122 & 118 & 98 & 108 & 122 & 120 & 108 \\
\hline SEM & 24 & 21 & 26 & 26 & 34 & 24 & 25 & 28 & 34 & 30 \\
\hline \multicolumn{11}{|c|}{ Vitamin $\mathrm{E}(\mu \mathrm{mol} / \mathrm{mmol}$ cholesterol $)$} \\
\hline Allopurinol & 5.2 & 5.2 & 5.2 & 5.0 & 5.3 & 5.1 & 5.1 & 4.9 & 4.9 & 5.2 \\
\hline SEM & 0.4 & 0.4 & 0.4 & 0.3 & 0.2 & 0.3 & 0.3 & 0.4 & 0.2 & 0.4 \\
\hline Placebo & 5.5 & 5.7 & 5.3 & 5.2 & 5.0 & 5.8 & 4.7 & 5.1 & 5.3 & 4.9 \\
\hline SEM & 0.5 & 0.5 & 0.4 & 0.4 & 0.4 & 0.5 & 0.5 & 0.4 & 0.4 & 0.5 \\
\hline \multicolumn{11}{|l|}{$\operatorname{AST}(\mathrm{U} / \mathrm{L})$} \\
\hline Allopurinol & 12 & 25 & 27 & 28 & 29 & 12 & 25 & 26 & 28 & 28 \\
\hline SEM & 2 & 3 & 4 & 4 & 4 & 2 & 4 & 4 & 4 & 4 \\
\hline Placebo & 9 & 22 & 22 & 23 & 25 & 9 & 22 & 23 & 24 & 26 \\
\hline SEM & 1 & 2 & 3 & 3 & 4 & 1 & 3 & 3 & 3 & 4 \\
\hline \multicolumn{11}{|l|}{$\operatorname{HBD}(\mathrm{U} / \mathrm{L})$} \\
\hline Allopurinol & 86 & 196 & 210 & 207 & 192 & 90 & 218 & 208 & 199 & 184 \\
\hline SEM & 9 & 31 & 33 & 29 & 21 & 10 & 37 & 32 & 27 & 17 \\
\hline Placebo & 93 & 206 & 206 & 209 & 230 & 101 & 209 & 203 & 228 & 236 \\
\hline SEM & 11 & 22 & 25 & 24 & 36 & 13 & 23 & 24 & 33 & 35 \\
\hline
\end{tabular}

$A-C S$, Arteriocoronary sinus difference; $C$, control sample obtained before aortic crossclamping; 30-600, seconds after final crossclamp; $S E M$, standard error of the mean; $A S T$, aspartate transaminase; $H B D$, hydroxybutyrate dehydrogenase.

between the two treatment groups. Vitamin $\mathrm{E}$ loss by the myocardium (area under the curve) was independent of net cardiac enzyme release (multivariate regression analysis) and aortic crossclamp duration (Spearman's test) in the placebo group and in both treatment groups when combined.

Cardiac enzymes. Both aspartate transaminase and hydroxy butyrate dehydrogenase levels were significantly elevated with respect to the control level at each time point during reperfusion (Table VI). No further increase was documented during the first 10 minutes of reperfusion. The net release of cardiac enzymes is almost identical for both groups. Cardiac enzyme release did not correlate with vitamin $\mathrm{E}$ loss or duration of aortic crossclamping for the group as a whole or for either of the treatment groups when considered separately.

\section{Discussion}

The main findings of this study are that allopurinol pretreatment produces an improvement in early postoperative cardiac function and a reduction in peroperative lipid peroxidation. Only a small, nonsignificant reduction in the net myocardial loss of vitamin E occurred, and no reduction in early myocardial enzyme loss was found.

Allopurinol pretreatment of patients undergoing bypass procedures has previously been reported to reduce postoperative mortality, ${ }^{22}$ inotrope usage, ${ }^{22,}{ }^{23}$ and the frequency of arrhythmias. ${ }^{23}$ In two other trials, structur- $\mathrm{al}^{31}$ and biochemica ${ }^{24}$ evidence for reduced perioperative myocyte damage was found in patients receiving prophylactic allopurinol. The findings presented here- a significant reduction in inotrope usage and a greater improvement of hemodynamic performance over the first postoperative day-are consistent with the results of previous studies. The low dose of allopurinol used in this study and in two of the previously mentioned studies ${ }^{22,31}$ almost certainly excludes direct free radical scavenging as the mechanism of benefit. ${ }^{25}$

Preferential use of vasodilators in the active treatment group is one potential mechanism that might explain the greater cardiac output and more rapid rewarming observed in the allopurinol group. Table III shows that nitrate administration was almost identical in the two groups over the first 24 hours after operation. Furthermore, the left ventricular stroke work indexes were higher in the allopurinol group, and the cardiac indexes remained higher in the allopurinol group after full rewarming had been achieved in both groups. From these data, it is clear that improved hemodynamic performance gave rise to the more rapid increase in peripheral temperature and not the reverse.

In the study presented here, significant lipid peroxidation during myocardial reperfusion was found only in the placebo group. Pretreatment with allopurinol attenuated the increase in TBArs levels in arterial and coronary sinus blood. As in our previous study ${ }^{13}$ and in the study of Dav- 


\begin{tabular}{rrrrr}
\hline \multicolumn{5}{c}{$A-C S$} \\
\hline \multicolumn{1}{c}{30} & \multicolumn{1}{c}{120} & 300 & 600 \\
\hline 2 & 8 & 5 & -6 & 7 \\
6 & 5 & 4 & 4 & 9 \\
4 & 10 & 8 & -2 & -10 \\
2 & 5 & 4 & 10 & 6 \\
& & & & \\
-0.1 & -0.1 & -0.4 & -0.1 & -0.1 \\
0.2 & 0.2 & 0.2 & 0.2 & 0.2 \\
0.2 & -0.9 & -0.2 & -0.1 & -0.1 \\
0.2 & 0.3 & 0.2 & 0.2 & 0.4 \\
& & & & \\
0.4 & -0.8 & -0.4 & -0.4 & -0.6 \\
0.8 & 1.3 & 0.5 & 0.4 & 0.6 \\
-0.1 & 0 & 0.6 & 0.7 & 0.5 \\
0.5 & 0.6 & 0.4 & 0.6 & 2 \\
& & & & \\
4 & 22 & -2 & -7 & -8 \\
7 & 15 & 4 & 4 & 6 \\
9 & 3 & -2 & 19 & 6 \\
4 & 3 & 4 & 12 & 29 \\
\hline
\end{tabular}

ies and associates, ${ }^{12}$ systemic radical activity appears to dominate because TBArs levels rose more rapidly ( 30 seconds and 2 minutes, Table VI) in the arterial circulation and no net arteriocoronary sinus difference was found in either group at any time point. The net release of products of peroxidation was, however, significantly attenuated in the coronary sinus blood $(p<0.02)$ but not in the systemic circulation $(p<0.15)$ by the use of allopurinol.

A possible explanation for the data presented is that the effects of extracorporeal circulation and consequent hypoperfusion of organs such as the liver and the lung is the stimulus for lipid peroxidation. The enzyme xanthine dehydrogenase is degraded to xanthine oxidase in these hypoperfused organs and is the main source of free radical generation (thus explaining the reduction with allopurinol). During the minutes to hours after bypass, the heart is perfused with toxic radical by-products from the liver and lung, but levels of these toxins have been substantially reduced in the allopurinol group. It is known from several authors that the heart is especially vulnerable to oxidative attack in the phase early after bypass. ${ }^{1416,19,20}$

The early myocardial loss of vitamin $E$ noted in our previous study ${ }^{13}$ has been confirmed in this study. Baseline vitamin $E$ levels were not predictive of the highest rates of lipid peroxidation in this study, even when one considers the placebo group alone. Furthermore, aortic crossclamping times were not predictive of myocardial vitamin $\mathrm{E}$ loss. These latter findings are in contrast to our previous results. ${ }^{13}$ One important difference between these two studies is that, in the previous study, all operations were performed by the same surgeon. For practical reasons, four different surgeons were involved in the present study. Variations in practice, handling of the heart, and, possibly most importantly, venting of the heart (routinely performed by two of the surgeons) may be obscuring such relationships.

It is evident that the group studied is far from homogeneous. Patients underwent operations performed by four different surgeons with the use of two methods of myocardial protection; patients also differed with respect to degree of myocardial impairment, number of diseased vessels, and the duration of ischemic insult. With respect to each of these potential sources of bias, data have been provided to show that their distribution between the treatment groups was entirely random and did not influence the outcome significantly.

In conclusion, low-dose allopurinol pretreatment significantly improves the recovery of myocardial function in the first postoperative day while reducing peroperative lipid peroxidation. It is proposed that the mechanism of action of allopurinol in this setting is inhibition of xanthine oxidase activity. The weight of available evidence suggests that lipid peroxidation during bypass arises predominantly from noncardiac sources.

We are indebted to Sir Professor M. Yacoub, A. Khagani, and A. Rees for permission to study their patients.

\section{REFERENCES}

1. Bolli R, Hartley CJ, Chelly JE, et al. An accurate nontraumatic ultrasonic method to monitor myocardial wall thickening in patients undergoing cardiac surgery. J Am Coll Cardiol 1990;15:1055-65.

2. Reduto LA, Lawrie GM, Reid JW, et al. Sequential postoperative assessment of left ventricular performance with gated blood pool imaging following aortocoronary bypass surgery. Am Heart J 1981;101:59-66.

3. Bolli R, McCay PB. Use of spin traps in intact animals undergoing myocardial ischaemia/reperfusion: a new approach to assessing the role of oxygen radicals in myocardial "stunning". Free Rad Res Commun 1990;9:169-80.

4. Baker JE, Felix CC, Olinger GN, Kalyanaraman B. Myocardial ischaemia and reperfusion: direct evidence for free radical generation by electron spin resonance spectroscopy. Proc Natl Acad Sci U S A 1988;85:2786-9.

5. Ferrari R, Ceconi C, Curello S, et al. Oxygen-mediated myocardial damage during ischaemia and reperfusion: role of the cellular defences against oxygen toxicity. $\mathrm{J}$ Mol Cell Cardiol 1985;17:937-45.

6. Arduini A, Mezzetti A, Porreca E, et al. Effect of ischaemia and reperfusion on antioxidant enzymes and inner mito- 
chondrial membrane proteins in perfused rat heart. Biochim Biophys Acta 1988;970:113-21.

7. Lesnefsky EJ, Repine JE, Horwitz LD. Oxidation and release of glutathione from myocardium during early reperfusion. Free Radic Biol Med 1989;7:31-5.

8. Bolli R, Jeroudi MO, Patel BS, et al. Marked reduction of free radical generation and contractile dysfunction by antioxidant therapy begun at the time of reperfusion. Circ Res 1989;65:607-22.

9. Ambrosia G, Weisfeldt ML, Jacobus WE, Flaherty JT. Evidence for a reversible oxygen radical mediated component of reperfusion injury: reduction by recombinant human superoxide dismutase administered at the time of reflow. Circulation 1987;75:282-91.

10. Mehta JL, Nichols WW, Donnelly WH, et al. Protection by superoxide dismutase from myocardial dysfunction and attenuation of vasodilator reserve after coronary occlusion and reperfusion in dog. Circ Res 1989;65:1283-95.

11. Koerner JE, Anderson BA, Dage RC. Protection against postischaemic myocardial dysfunction in anaesthetised rabbits with scavengers of oxygen derived free radicals: superoxide dismutase plus catalase, N-2-mercaptopropional glycine and captopril. J Cardiovasc Pharmacol 1991; 17:185-91.

12. Davies SW, Underwood S, Wickens D, Feneck R, Dormandy T, Walesby R. Systemic pattern of free radical generation during coronary bypass surgery. $\mathrm{Br}$ Heart $\mathbf{J}$ 1990;64:236-40.

13. Coghlan JG, Flitter WD, Clutton SM, Ilsley CD, Rees A, Slater TF. Lipid peroxidation and changes in vitamin $E$ levels during coronary artery bypass grafting. J THORAC Cardiovasc Surg 1993;106:268-74.

14. Ferreira R, Llesuy S, Milei J, et al. Assessment of myocardial oxidative stress in patients after myocardial revascularisation. Am Heart J 1988;115:307-12.

15. Ferreira R, Burgos M, Milei J, et al. Effect of supplementing cardioplegic solution with deferoxamine on reperfused human myocardium. J Thorac Cardiovasc Surg 1990; 100:708-14.

16. Ferreira R, Burgos M, Llesuy S, et al. Reduction of reperfusion injury with mannitol cardioplegia. Ann Thorac Surg 1989;48:77-84.

17. Royston D, Fleming J, Desai J, Westaby S, Taylor K. Increased production of products of peroxidation in association with cardiac operations. J THORAC CARDIOvASC SURG 1986;91:759-66.
18. Cavarocchi NC, England MD, O'Brien JF, et al. Superoxide generation during cardiopulmonary bypass: Is there a role for vitamin E? J Surg Res 1986;40:519-27.

19. Ferreira R, Alfieri O, Curello S, et al. Occurrence of oxidative stress during reperfusion of the human heart. Circulation 1990;81:201-11.

20. Weisel RD, Mickle DAG, Finkle CD, et al. Myocardial free radical injury after cardioplegia. Circulation 1989; 80(Suppl):III14-18.

21. Esterbauer H, Schaur RJ, Zollner H. Chemistry and biochemistry of 4-hydroxynoneal, malonylaldehyde and related aldehydes. Free Rad Biol Med 1991;11:81-128.

22. Johnson W, Kayser K, Brenowitz J, Saedi S. A randomized controlled trial of allopurinol in coronary bypass surgery. Am Heart J 1991;121(Pt 1)20-4.

23. Rashid HA, Williamolosson $\mathrm{G}$. Influence of allopurinol on cardiac complications in open heart operations. Ann Thorac Surg 1991;52:127-30.

24. Tabayashi K, Suzuki Y, Nagamine S, Ito $Y$, Sekino $Y$, Mohri H. A clinical trial of allopurinol (Zyloric) for myocardial protection. J ThORAC CARDIOvaSC SuRg 1991; 101:713-8.

25. Downey MJ, Hearse DJ, Yellon MD. The role of xanthine oxidase during myocardial ischaemia in several species including man. J Mol Cell Cardiol 1988;20(Suppl 2):5563.

26. Muxfeldt $M$, Schaper $W$. The activity of xanthine oxidase in the hearts of pigs, guinea pigs, rabbits, rats and humans. Bas Res Cardiol 1987;82:486-92.

27. Eddy LJ, Stewart JR, Jones HP, Engerson TD, McCord JM, Downey JM. Free radical-producing enzyme, xanthine oxidase, is undetectible in human hearts. Am $\mathbf{J}$ Physiol 1987;253:H709-11.

28. Grum CM, Gallagher KP, Kirsh MM, Shlafer M. Absence of detectible xanthine oxidase in human myocardium. $J$ Mol Cell Cardiol 1989;21:263-7.

29. Yagi K. Assay for serum lipid peroxide level and its clinical significance. In: Yagi K, ed. Lipid peroxides in biology and medicine. New York: Academic Press, 1982;223-41.

30. Burton GW, Webb A, Ingold KU. A mild, rapid, and efficient method of lipid extraction for use in determining vitamin E/lipid ratios. Lipids 1985;20:29-39.

31. Adachi H, Motomatsu K, Yara I. Effect of allopurinol (Zyloric) on patients undergoing open heart surgery. Jpn Circ J 1979;43:395-401. 